\title{
DEBATE \\ Situación actual de los derechos de los niños, niñas y adolescentes en Chile
}

\section{Introducción}

Uno de los debates sobre los derechos humanos que más atención ha tomado en los últimos años, y de una manera persistente es aquel que se refiere a la situación de los derechos de los niños, niñas y adolescentes. Este debate está marcado por la percepción de la insuficiencia de la respuesta estatal, simbolizada en la crisis del Servicio Nacional de Menores (Sename) en cuanto al cuidado de niños más vulnerables del país. Sin embargo, esa crisis no se limita a la falta de recursos de dicha institución: es sintomática de la escasa preocupación de la sociedad por el cumplimiento de los deberes los derechos de los niños.

Hace más de una década que se debate acerca de la reestructuración del Servicio Nacional de Menores, y cierto consenso en que todo el sistema requiere ajustes estructurales. El debate actual sobre el Sename guarda una continuidad con largas discusiones sobre las responsabilidades del Estado con la infancia, pero recibió un nuevo enfoque desde la ratificación de la Convención sobre los Derechos del Niño, en cuanto dicho enfoque requiere un compromiso del Estado con derechos humanos especiales y reforzados en atención a la mayor vulnerabilidad de la infancia y adolescencia. Ahora bien, a partir de ese momento cuanto más exigente el debate, mayor es la decepción debido a la insuficiente labor del Estado en esta materia y a la apatía de la sociedad chilena.

Un informe sobre Chile publicado en julio de 2018 del Comité de Derechos del Niño de las Naciones Unidas, apunto a la responsabilidad del Estado por las graves violaciones de los derechos enunciados en la Convención sobre los Derechos del Niño, considerando que el sistema de protección residencial de Chile ha significado una amplia vulneración de derechos de miles de niños, niñas y adolescentes (NNA) bajo tutela del Estado durante un largo periodo de tiempo. ${ }^{1}$

En este contexto, el Anuario de Derechos Humanos ha invitado a tres expertos en

1. Comité de Derechos del Niño, Informe de la Investigación relacionada en Chile, en virtud del artículo 13 del Protocolo Facultativo de la Convención sobre los Derecho del Niño relativo a un procedimiento de comunicaciones, 2018. Disponible en http://bit.ly/2DuPvku. 
derechos del niño, quienes desde diferentes miradas y experiencias — derecho de familia, derechos del niño, responsabilidad penal adolescente-, nos explican su visión sobre la situación actual de los derechos de la infancia y adolescencia en Chile y sus perspectivas de cambio.

\section{Pregunta 1. Violaciones a los derechos de los niños, niñas y adolescentes}

¿Cuáles son los principales ámbitos en los que se verifican las más graves violaciones a los derechos humanos de niños, niñas y adolescentes en la actualidad?

\section{Fabiola Lathrop}

Si bien los niños, niñas y adolescentes sufren una serie de menoscabos en sus derechos, los más graves, aunque no los más importantes en términos numéricos, son las vulneraciones que sufren los niños que viven en medios alternativos a su entorno familiar. El sacrificio de su derecho a la vida familiar, transformado en la regla general en situaciones de vulneraciones graves de sus derechos cometidas en el entorno familiar o social, implica la internación en lugares que no cuentan con estándares mínimos de seguridad, de respeto a su integridad física o psicológica. Ésta es la violación más grave de derechos de niños, niñas y adolescentes en Chile, desde el punto de vista de que, en estos casos, la vulneración de derechos viene por parte del propio Estado.

Pero también es cierto que los niños sufren violaciones a sus derechos en los propios ámbitos escolares. También se dan vulneraciones en el acceso por parte de ciertos niños, fundamentalmente con algún tipo de discapacidad, o niños que están en una situación de definición de su identidad de género, a la salud en general, y en especial a la mental. Y, por cierto, lo cual es tan grave como importante, el hecho de que los niños sufren mucha violencia física y psicológica en sus propias familias. Las cifras que arrojan los estudios de Unicef son impresionantes. Cerca del 70\% de nuestros niños dice haber sufrido algún tipo de violencia por parte de su padre y/o madre. El maltrato es transversal al nivel socioeconómico de las familias.

También los niños en Chile sufren violación en su derecho de participación, al no haber estructuras formales, a nivel estatal ni social, de participación, en donde puedan expresar su derecho a ser oídos en distintos temas.

También, además de la participación en general, hay vulneración de derechos respecto de una concreta dimensión de este derecho, la de ser oído en la defensa en juicio. El hecho de que no exista hoy una estructura de defensa judicial de los derechos de los niños sometidos a un proceso a través de un abogado que represente sus intereses, es también una deuda del Estado chileno. La Defensoría de la Niñez creada hace muy poco viene a paliar eso, pero su labor se realiza más bien respecto de inte- 
reses de carácter colectivo, como la promoción y difusión de los derechos humanos, seguimientos, denuncias, pero eso no implica que vaya a haber una representación de los derechos del niño a nivel nacional en juicios o donde estén involucrados sus intereses, o que el propio niño haga valer un derecho ante un tribunal de la república. Eso no está garantizado, ni en la práctica ni en el texto legal.

\section{Gonzalo Berríos}

Mi opinión al respecto se centrará en la situación de los niños y niñas que han infringido la ley penal. Creo que hay violaciones a los derechos humanos, en primer lugar, en el caso del uso excesivo de la medida cautelar de internación provisoria, toda vez que esa medida cautelar debiese ser excepcional, porque implica la privación de libertad de los adolescentes. Dicha privación de libertad es una decisión que los instrumentos de derechos humanos indican que debe ser tomada solo como último recurso y por el período más breve que proceda. Después de once años que lleva funcionando el sistema penal juvenil, tenemos un problema persistente en este punto porque alrededor del ochenta o noventa por ciento de los jóvenes que pasaron por internación provisoria no terminan condenados a una pena privativa de libertad, lo cual está prohibido por la ley, y no hay reformas legales en curso que ataquen eficazmente este problema.

Otro ámbito de importantes violaciones a los derechos humanos lo encontramos en las condiciones materiales de los centros privativos de libertad de los adolescentes. Son recintos precarios, mal equipados y con poco personal especializado. Hay una grave omisión por parte del Estado en materia de satisfacción de derechos y oferta socioeducativa a niveles tan básicos como es la educación formal. También hay omisiones importantes en el ámbito de la salud de los adolescentes privados de libertad, y en especial carencias relacionadas con la salud mental. No hay una oferta suficiente para la cantidad de jóvenes que están en el sistema, y que tienen problemas de salud mental.

Y lo último, que también es recurrente en este ámbito, son los malos tratos provenientes de quienes se encuentran a cargo de los adolescentes en los centros. Este es un problema latente que cada cierto tiempo se visibiliza porque fallan los protocolos, fallan los mecanismos de prevención y porque tampoco los mecanismos de sanción son lo suficientemente serios para favorecer prácticas de gestión de conflictos no violentas.

\section{Miguel Cillero}

Creo que en Chile hay un punto inicial que es necesario siempre relevar y no olvidar, pues en nuestro país nacer y crecer en pobreza sigue siendo uno de los elementos, 
aunque no el único ni el exclusivo, determinante respecto a la posibilidad de ejercer efectivamente los derechos de los niños y alcanzar un pleno desarrollo como persona. La pobreza sigue afectando de un modo desproporcionadamente alto a los niños más que a otros segmentos de la población, y es, en sí misma, una grave vulneración de derechos.

En segundo término, tenemos ciertas formas de exclusión permanente de colectivos o grupos que afectan particularmente a la infancia, por ejemplo, la discriminación que afecta a los niños indígenas, la estructura patriarcal de nuestra sociedad que afecta a niños, niñas y adolescentes independientemente de su sexo o identidad de género, pero particularmente se expresa en violencia en las relaciones familiares y discriminación por machismo, homofobia u otras formas de intolerancia a la diversidad sexual. Otro tema emergente es la infancia migrante.

La estructura de la sociedad chilena es una estructura excluyente, y las sociedades excluyentes y segregadoras se construyen desde la infancia y la adolescencia. Esa estructura golpea además muy fuertemente a los niños, niñas y adolescentes.

Entrando a cuestiones más específicas, claramente nuestros sistemas de protección infantil dan muestras evidentes de una fuerte, y más o menos permanente, vulneración de derechos, tanto en el ámbito de justicia penal adolescente como particularmente en el sistema de protección vinculado al Servicio Nacional de Menores (Sename). Ahí tenemos un problema muy serio.

Además, tenemos algunas dificultades muy importantes en el acceso de los niños, niñas y adolescentes a salud mental, desde aquellas problemáticas más delicadas que requieren atención psiquiátrica especializada, como también en asuntos menos intensos pero generalizados como depresión leve, problemas de consumo de alcohol y drogas, tratamientos en general de una serie de otras cuestiones de salud mental quizás de no tanta gravedad, pero sí de una enorme prevalencia.

Y claramente el tercer ámbito que uno puede destacar fuertemente es la prevalencia del maltrato y la violencia en contra de los niños. Éste es un problema muy extendido en el país según diversas investigaciones en ese sentido, y no existen programas preventivos adecuados ni mecanismos institucionales para poder enfrentarlo. En este ámbito hay dificultades en prevención y tratamiento. Hasta ahora lo más visible es la crisis del Sename, pero todo indica que los casos del Sename son solo la punta de un iceberg que está empezando a emerger. Hay necesidad de avanzar más en identificar a las víctimas, profundizar estudios de polivictimización y desarrollar estrategias concretas para enfrentar y superar los graves efectos de la violencia sobre el desarrollo de los niños, particularmente en aquellos niños que sufren traumas complejos producto de la violencia a que han sido sometidos, tanto en contextos familiares, como escolares e institucionales, como en los contextos territoriales de violencia o de privación social en que han vivido. 


\section{Pregunta 2. Problemas normativos}

¿Cuáles son los principales problemas normativo-institucionales en el ámbito de las violaciones a los derechos humanos de niños, niñas y adolescentes?

\section{Fabiola Lathrop}

El principal problema normativo es que en Chile no existe una ley de protección integral de los derechos del niño. No se trata de una ley que establezca solo un catálogo de derechos, porque para eso está la Convención de los Derechos del Niño, sin perjuicio de que se pueda profundizar en una u otra área de la Convención a nivel interno. En ese sentido, es necesario que haya una ley de protección integral que esté asociada a instituciones, a estructuras que formen un sistema de protección. Es vital que exista una ley de protección integral entendida no solo como un catálogo de derechos, sino como un cuerpo que ordene la institucionalidad general de la infancia, y que tenga un ente rector ubicado en un determinado organismo.

Chile es el único país de América Latina que no tiene ley de protección integral de los derechos del niño. Entonces, el principal problema es la carencia de un estatuto protector, pero asociado siempre a garantías primarias y secundarias de protección de esos derechos. No obstante, las iniciativas legislativas que han existido en Chile han sido siempre aisladas, los proyectos de ley no son presentados como parte de una verdadera agenda de la infancia. Si bien se quiso hacer así en el gobierno anterior, finalmente eso se frustró porque no había voluntad política. El proyecto de Ley del Sistema de Garantías de Derechos de la Niñez se presentó sin informe financiero, ni mostraba todo el sistema administrativo y judicial de protección de los derechos, y eso generó ciertas reticencias. ${ }^{2}$

En definitiva, una ley que vaya asociada a la determinación de las instituciones y de garantías específicas de los derechos del niño, tanto a nivel administrativo como judicial, es el principal problema desde el ámbito jurídico y de políticas públicas que presenta Chile en este tema.

\section{Gonzalo Berríos}

A nivel institucional está claro que el actual Servicio Nacional de Menores como institución no da abasto y no tiene cómo hacerlo bajo su actual diseño. Por eso son muy positivas las reformas legales que están en curso desde 2017. La creación de un nuevo servicio es una demanda que viene ya desde el año 2000 , fundada en la necesidad de

2. Véase el Proyecto de Ley de Sistema de Garantías de los Derechos de la Niñez, Boletín 10315-18, presentado en septiembre de 2015, y que se encuentra en segundo trámite constitucional en el Senado. Disponible en http://bit.ly/2yYuCdB. 
separar y especializar los servicios, es decir, un servicio especializado para el ámbito de protección de la infancia - aunque me parece que hay una cierta regresión en su alcance en las últimas indicaciones legislativas- y otro servicio especializado para adolescentes infractores de la ley penal. ¿Por qué es necesario eso? Por especialidad. Si bien para todos los niños y niñas hay necesidades comunes, también hay habilidades, ofertas y capacidades que son específicas. Esto debiera implicar mejorar la coordinación interinstitucional, ya que cualquier servicio, sea el actual o el futuro, no puede hacer su trabajo por sí mismo, sino que necesita coordinarse con el Ministerio de Educación, de Salud, de Trabajo, y para eso necesita tener poder, necesita tener fuerza institucional para lograr coordinar esa oferta y ponerla a disposición de la integración social de los adolescentes infractores.

Muchas veces falta voluntad política para promover la reinserción social. Entre un servicio como el Sename, o su sucesor, y el Ministerio de Educación, hay un problema de poder y un problema de recursos. El Ministerio de Educación seguramente está preocupado de los millones de estudiantes del sistema educativo formal, mas no así de algunos centenares de jóvenes privados de libertad. Ahí hay un problema de voluntad política y también de aseguramiento legal, no solo institucional.

Otro problema normativo se da, por ejemplo, en el caso de la internación provisoria, pues falta algún tipo de mecanismo en la propia ley que permita disminuir el uso de esta medida cautelar. Y eso no está previsto en el proyecto de ley en trámite, no hay ningún mecanismo propio de la justicia juvenil que permita al menos su revisión periódica. Sobre esto la Corte Interamericana de Derechos Humanos, en el caso Mendoza y otros con Argentina, señaló como estándar la creación de mecanismos de revisión periódica, y como país no lo estamos respetando. Ahí hay un déficit importante.

\section{Miguel Cillero}

Chile carece de una normativa integral que garantice efectivamente el ejercicio de los derechos de los niños. Hemos tenido desde el 2005 varios proyectos e intentos de reforma legislativa, todas la cuales han terminado en un fracaso. Han fracasado directamente, lo que no quiere decir que no haya áreas específicas en la que se ha avanzado y de manera importante, pero yo diría que el principal problema es hoy no tener una normativa marco que ordene toda la protección de la infancia y garantice el ejercicio de los derechos de los niños. Esa asimetría en el ejercicio de las libertades se ha ido resolviendo fragmentariamente y debe ser resuelta en una primera línea por una ley de garantías de los derechos de los niños, niñas y adolescentes y, en segundo término, hay que establecer un sistema de garantías institucionales normativas, presupuestarias y programáticas adecuadas. Hay que modificar fuertemente la institucionalidad. En Chile todavía tenemos vigente una ley de menores y una institucionalidad que heredamos, más o menos, desde la década de los cincuenta y sesenta, y 
desde allí hemos ido haciendo pequeños cambios y tenemos un problema muy serio con el Servicio Nacional de Menores, cuya reforma es un asunto que ha resultado muy difícil de concretar.

\section{Pregunta 3. Enfoques de derechos y de vulnerabilidad}

¿En qué medida pueden aportar los enfoques de derechos o de vulnerabilidad para orientar la intervención estatal en temas de niños, niñas y adolescentes?

\section{Fabiola Lathrop}

La Convención Americana de Derechos Humanos establece la obligación para los Estados, en su artículo 19, de tomar medidas especiales de protección cuando se trata de niños, y esto dice relación con que los niños se encuentran en una situación particular que requiere de la adopción de todo tipo de medidas, cualquiera sea el ente, cualquiera sea la naturaleza de esa medida, que proteja, que haga efectivos, los derechos del niño.

Además, cuando hay un niño en especial situación de vulnerabilidad, cuando pertenece a una determinada minoría, cuando está en una situación de pobreza, en una situación de desarraigo o de migración, el enfoque de la vulnerabilidad es muy pertinente, y en una sociedad como la chilena que está viviendo en los últimos años un cambio tan profundo como es la migración, este enfoque se vuelve aún más importante.

Entonces, de hecho, hay autores que han señalado, y esto está documentado, cómo el aseguramiento de los derechos de los niños que están en una situación particular, en una doble vulnerabilidad o de minoría, gatilla muchas veces que el estándar de protección de derechos de los adultos mejore. Esto se explica porque un niño, que está en una situación de carencia de derechos sociales, por ejemplo, y que recibe una respuesta oportuna por parte del Estado para ponerlo en una situación de equivalencia con niños que no están en esa doble o triple situación de vulnerabilidad, mejora, a su vez, los derechos de los adultos que están en su entorno.

Así las cosas, este enfoque de la vulnerabilidad, de especialidad en la satisfacción de derechos, tiene un efecto directo en la mejora de la condición de vida de todas las personas.

\section{Gonzalo Berríos}

En el caso de la Ley de Responsabilidad Penal Adolescente (LRPA), con todos sus déficits, hay que reconocer que desde su origen está concebida y basada en un enfoque de derechos. Hay una discusión por cierto sobre su suficiencia, pero el enfoque de derechos está presente en la ley. Y donde la ley o el funcionamiento real del sistema 
se alejan de dicho enfoque, han sido los defensores y los tribunales los que en muchos casos han ayudado a fortalecer los derechos con nuevas interpretaciones de la ley.

Respecto del rol de la vulnerabilidad, lo interpreto como un llamado de atención para reforzar los derechos y no para disminuirlos o debilitarlos. Por ejemplo, un adolescente puede verse como muy vulnerable para tomar ciertas decisiones por falta de experiencia o conocimientos, pero eso no lo inhabilita para tomar la decisión que lo involucra. Más bien la vulnerabilidad nos obligaría a pensar qué mecanismos especiales de protección para la toma de decisiones deberíamos crear. Yo soy cuidadoso con el tema de vulnerabilidad, porque si bien es compatible con un enfoque de derechos, puede ser un arma de doble filo, como el interés superior del niño, si no se asegura tal compatibilidad. Por ejemplo, la idea de que «si son vulnerables, nosotros tenemos que decidir por ellos». No, esa vulnerabilidad de alguna manera hay que transformarla para asegurar que esa toma de decisiones sea efectivamente libre e informada.

\section{Miguel Cillero}

El Estado y la sociedad deben asumir una nueva perspectiva referente a afrontar las políticas de infancia basándose en el enfoque de derechos y desarrollando un conjunto de garantías reforzadas de los derechos de los niños. Pero también dentro de la protección de la infancia es necesario re-reforzar u otorgar una supraprotección a algunos grupos de niños, niñas y adolescentes en los que se podría dar una mayor vulnerabilidad, o que directamente ya existe. El enfoque que hay que incorporar en la perspectiva de las políticas de la infancia es más claramente un enfoque de derechos, que se basa en el conjunto de normas internacionales de protección de los derechos de la infancia.

El enfoque de derechos se ha de vincular con el enfoque de desarrollo humano y, en ese marco integral, debe generar un rol protector frente a estos grupos vulnerables, que se expresa en un conjunto de garantías institucionales, programáticas y financieras. Para ello se debe considerar la interseccionalidad, pero no solamente sobre la idea de vulnerabilidad, sino en forma más global. Es muy relevante la articulación entre el enfoque de género y el enfoque de derechos y las cuestiones relativas a pueblos indígenas, minorías culturales y migrantes, entre otros.

\section{Pregunta 4. Servicio de Protección a la Infancia}

¿Cree que un Servicio de Protección a la Infancia podrá subsanar las deficiencias que presenta el Sename? ¿Qué funciones y características debería tener este Servicio? ¿Qué rol deben jugar las instituciones privadas que han sido colaboradoras del Sename en un nuevo sistema de protección de la infancia? 


\section{Fabiola Lathrop}

Sí. El Servicio de Protección Especializada, así como está en el proyecto de ley actual, es una gran iniciativa. Si va asociado a una efectiva presencia territorial, local, a través de la cual el niño pueda acceder a otras estructuras que inicialmente le son más lejanas, para que se satisfagan sus derechos, yo creo que es pertinente.

El Servicio de Protección a la Infancia que está plasmado en el proyecto tiene un enfoque muy particular, a mi juicio muy bueno. Podría uno pensar que porque es un gobierno más de derecha es así, pero independientemente del color político, el que el enfoque esté en la familia, en la intervención progresiva, no radical, sino que progresiva de esas familias, a través de medidas que no necesariamente implican una vulneración a la esfera de la familia, de la responsabilidad parental, es muy positivo.

La participación familiar integral durante este proceso puede conseguirse a través de distintos caminos: a través de una medida de acción educativa a la familia, incluso una ayuda económica, una beca, que no implique vulnerar otros derechos.

Entonces, cuando existe un catálogo abierto, basado en una intervención en la que se hace participar a la familia, con un enfoque comunitario, eso es muy bueno. Entonces, ese enfoque nuevo, que no lo había visto antes en otras iniciativas, me parece positivo si es que va de la mano con otras iniciativas además de la ley de protección integral, como la creación del Servicio de Reinserción, con un fortalecimiento de las medidas y funciones de la actual Defensoría y una representación de los derechos del niño a nivel nacional, me parece que sí.

Ahora, no hay que ser ingenuos, esto no es fácil. Sin embargo, si logramos que el niño pueda acceder de verdad, como cualquier adulto, a una acción de protección pertinente para su propia realidad, con un acceso fácil, esto va a cambiar la lógica del ciudadano chileno, y la lectura que en general se hace de los derechos.

Ahora bien, es vital entender que hay que partir por los niños, porque a través de ellos se promueven en la población adulta estos derechos. La ley de garantías, por ejemplo, no se concretó, entre otras cosas porque se fortalecía un sistema administrativo de protección de derechos, y en Chile no tenemos un Estado administrador muy potente, porque hay una lógica de judicializar los problemas.

Lo que recomiendan todos los estándares y organismos de derechos humanos, como la Comisión Interamericana de Derechos Humanos y el Comité de Derechos del Niño, es que los sistemas sean no totalmente administrativos, sino que haya una mixtura entre lo administrativo y lo judicial. Esto no es porque se quiera quitar poder a la función judicial, sino que tiene que ver con fortalecer estructuras que son más pertinentes para intervenir en ciertas situaciones, y los niños son prueba de ellos. El sistema administrativo es menos invasivo, teóricamente, más pertinente, tiene presencia local, está menos estructurado y eso es bueno porque da libertad para responder al dinamismo en las relaciones sociales. Por ejemplo, una familia puede abando- 
nar un programa por alguna razón justificada, y eso, si el aparato fuera netamente judicial, como es ahora, implicaría que están incumpliendo una medida, entonces la respuesta judicial es más violenta. En cambio, si la intervención es administrativa, hay una posibilidad de hacerle un seguimiento mucho mayor.

Es necesario precisar que los jueces no están para distribuir ofertas administrativas, que es lo que hacen hoy. Para eso debieran existir otros mecanismos, otros instrumentos. Entonces, sí creo que podría subsanar las deficiencias que presenta el Sename, y no solo podría, sino que debe. Si el Sename se divide, el Servicio de Protección especializada debe suplir esas deficiencias. No queda otra alternativa.

Ahora, en cuanto a las instituciones privadas que han sido colaboradoras del Sename, teóricamente un buen sistema de protección de derechos no tiene por qué tener monopolizada estatalmente la oferta de los servicios. O sea, la mayoría de los sistemas que funcionan bien son mixtos. Lo que pasa es que en Chile la regla es la contraria: el $96 \%$ de la oferta está en los privados, y la que no es privada es la que ha estado precisamente más denostada por la opinión pública, y legítimamente, por la muerte de Lisette. ${ }^{3}$ Entonces, el que el Estado lo haga no es garantía de que funcione bien. Es mejor si la sociedad civil se vincula a esta tarea, pero cuando lo hace tiene que hacerlo, primero, con recursos razonables, suficientes, no como ahora en que el incentivo está puesto no en la calidad sino en la cantidad por el subsidio que recibe, y con estándares de calidad y con fiscalización. Entonces, que se acrediten los organismos, cosa que no existe, y que haya un control, una supervigilancia, una fiscalización concreta y de verdad funcional, real - no como ahora, donde los programas se renuevan uno a otro sin mayores discusiones-, es esencial para un correcto funcionamiento de un sistema mixto.

Entonces, lo ideal es que el diseño esté construido no a propósito de la oferta de instituciones colaboradoras que ya existan, sino que, al revés, que sea el Estado el que exija los estándares, y estas agencias se ajusten a ellos. Hoy en día, dependiendo de los programas que existen es que se generan las directrices, y debe ser al revés, el Estado tiene que planear y diseñar.

Lo otro que me parece muy importante es crear nuevos programas que tienen que ver con el acompañamiento de los niños una vez que salen de las instituciones, porque hay allí una tierra de nadie. La preparación para la vida adulta independiente es una gran deuda. Se entiende que estemos centrados en primera infancia, pero esto también es una tarea pendiente, porque estos niños se insertan en la vida educativa, social o laboral muy mal después. Falta una mirada más holística.

3. Lisette Villa Poblete tenía once años cuando murió en un hogar bajo la administración directa del Sename, el CREAD Galvarino, en 2016. Además de las investigaciones criminales correspondientes, reavivó el debate sobre las capacidades del Sename para cumplir sus responsabilidades con la infancia vulnerable. 


\section{Gonzalo Berríos}

No es el ámbito de mi especialidad, pero vinculado a lo que decía antes, yo creo que sí es un paso relevante terminar con un único servicio y con lo que está de fondo detrás de eso. Creo que un único servicio ha favorecido una mirada algo confusa entre dos problemas que son distintos, aunque puedan tener puntos en común. El niño es una sola persona y tiene varias dimensiones, pero creo que es relevante precisamente que se especialice en ese ámbito. Ahí hay que ver por qué modelo se va a optar. El modelo que yo veo que está hoy día sobre la mesa, de acuerdo con las últimas indicaciones parlamentarias que se realizaron hace un tiempo atrás, es un servicio de protección que está muy focalizado hacia un cierto grupo de niños, los que están más afectados. Pero debiera haber un servicio que se dirija también a toda la infancia en distintos niveles de afectación de sus derechos.

Respecto del rol de las instituciones colaboradoras, preferiría un nuevo equilibrio respecto al papel histórico que han tenido las instituciones privadas, pero que no sea más un enfoque subsidiario y caritativo. Se puede trabajar con la sociedad civil, pero desde una política pública, bajo estándares que tienen que cumplir. El Estado más que subsidiarla debiera financiarla y controlar que efectivamente no estén lucrando con los recursos, que estos se destinen efectivamente a ese trabajo, y que además también exista una oferta propiamente pública o estatal que permita reequilibrar un poco este sistema. Porque siempre está el riesgo de que, si se controla mucho, una institución privada puede decir que bajo esas condiciones no trabaja y quedan de "rehenes» los niños y niñas. Hay una relación de poder fuerte que hay que regular de buena manera. En todo caso, aunque no era el objeto de la pregunta, en el ámbito penal soy partidario de un rol estatal mucho más fuerte terminando, por ejemplo, con que los delegados sean privados, pues debieran ser funcionarios públicos.

\section{Miguel Cillero}

Me referiré de modo abstracto y no a un proyecto en particular. Efectivamente Chile necesita un Servicio de Protección a la Infancia que reemplace al actual Sename, de eso no cabe ninguna duda. Es una reforma que considero necesaria. Parece que hay buenas razones para que ese diseño sea incluido dentro del marco de acción del Ministerio de Desarrollo Social. Primero, de acuerdo con la última reforma a la Ley Orgánica del Ministerio en que creó la Subsecretaría, se estableció a este Ministerio y al Consejo de Ministros Sociales de Infancia como el organismo coordinador y rector. A nivel general y dada esa condición, parece razonable que el Servicio dependa del Ministerio de Desarrollo Social. En segundo término, porque la Subsecretaria de la Niñez es un instrumento importante desde el cual poder dirigir una reforma completa y evitar que este servicio repita los mismos problemas que ha tenido el ac- 
tual Sename y, tercero, porque efectivamente ese servicio de protección especializada debiera vincularse estrictamente con programas más generales de protección social y las políticas públicas universales que se coordinan desde el Ministerio de Desarrollo Social, pero teniendo claro que es una política general y no solo para niños vulnerables, en cuanto se entiende el Ministerio de Desarrollo Social como un ministerio que se encarga de todos los niños y no solamente de los más vulnerables.

Así quedan delineadas las funciones que debiera tener este servicio: que provea una serie de prestaciones especializadas para casos de vulneración de los derechos de los niños y esas prestaciones especializadas las ejecute por sí mismo, articulando oferta pública o también a través de la participación de organismos colaboradores privados sin fines de lucro - que deben serlo efectivamente- para que ofrezcan determinadas prestaciones y programas de probada calidad y efectividad.

Nosotros hemos tenido un sistema de provisión mixta de programas de protección a la infancia y soy partidario de que continúe aquella forma de provisión, pero ella requiere profundas transformaciones, fundamentalmente en cuanto a que los programas administrados por privados y por el Estado, sean programas basados en evidencia, debidamente acreditados, con eficaces sistemas de monitoreo, con mecanismos de mejoramiento de gestión y auditoría, y con posibilidades de que los niños puedan efectivamente expresar sus opiniones sobre la intervención y que todos los niños, niñas y adolescentes puedan acceder a los programas sin discriminación.

Se deben desarrollar nuevas metodologías de intervención basadas en la evidencia, debidamente acreditadas. Es fundamental concentrarse en mejorar la calidad de las prestaciones con un sistema de financiamiento que la asegure. Por ello, hay que diseñar un nuevo sistema de financiamiento basado en un sistema de acreditación de los programas y cumplimiento de metas, donde la innovación sea un elemento central. Los programas deben efectivamente cumplir condiciones para ser acreditados, tanto en general como en particular, de acuerdo con cada línea programática. Además, el servicio debería simplificar las líneas programáticas actualmente vigentes en la Ley 20.032 y en el resto de la normativa del Sename.

Es necesario hacer un trabajo importante para ir desarrollando una parrilla programática integrada, un conjunto de programas más focalizados, menos fragmentados, centrados en el territorio y las personas. Es necesario orientar los programas a los colectivos infantiles en sus territorios con mucha más presencia local, pero no para tener un programa por cada localidad, sino para hacerse cargo articuladamente de todos los niños del territorio; y, por otro lado, el sistema debe basarse en la idea de la gestión de personas, con programas centrados en las personas y en los niños y sus familias.

Lo que actualmente está ocurriendo es una mera administración de programas en el Servicio Nacional de Menores, con una tendencia a seguir a los programas y no a las personas, y por eso pasa aquello tan dramático que cuando se pregunta cuántos 
niños murieron en el sistema nadie sabe, ni por qué ni cómo, y hay que empezar programa por programa a buscar. Esto sucede porque, en realidad, la gestión se hace por programa y en ese marco las personas - en este caso los niños, niñas y adolescentes - tienden a desaparecer como sujeto de preocupación del sistema.

\section{Pregunta 5. Nueva institucionalidad y responsabilidad penal}

Existe consenso en que el Servicio Nacional de Menores debe ser reestructurado para enfrentar las crisis de derechos humanos en la materia. ¿Cuáles considera usted que deberían ser los pilares de una nueva institucionalidad para el tratamiento de adolescentes infractores de ley?

\section{Fabiola Lathrop}

No soy experta en este tema. Lo que sé es que hay avances, que también el sistema de responsabilidad penal juvenil necesita modificaciones, y entiendo que eso también está avanzando. De hecho, el Departamento de Reinserción Social ya opera en el Ministerio de Justicia, antes de que se divida legalmente el Sename. Tengo la sensación de que el énfasis debe estar en la protección de los derechos de niños vulnerados. Hay vasos comunicantes entre el sistema de protección especial y el de Responsabilidad Penal Adoslecente, o sea, hay niños que han pasado por el sistema de protección especial que luego pueden entrar al sistema de Responsabilidad Penal Adolescente. Entonces, parece ser que, mientras más inviertes en lo primero, menos inversión tienes que poner en lo segundo, y, es más, hay un eslabón anterior. Mientras más se invierte en protección universal de derechos, menos se invierte en protección especial. Si todos los niños tuvieran, independientemente de su situación económica, o si están siendo vulnerado en sus derechos o no, garantizados sus derechos a la educación, al juego, a la salud, a la vida familiar, lógicamente existirían menos hipótesis de insatisfacción de derechos a un nivel grave.

\section{Gonzalo Berríos}

Creo que es clave un nuevo servicio que esté dirigido a los adolescentes infractores, que sea de alto nivel y con recursos suficientes para trabajar de buena manera. Eso implica no solo que en la base de la estructura podamos contar con mejores profesionales, más capacitados para trabajar con adolescentes infractores, sino que además la propia institución tenga capacidad de ir siempre un paso más allá. Por ejemplo, un buen departamento de estudios, que permitiera estar al día en los debates y en las experiencias internacionales y estar replicándolos inmediatamente en el estándar de funcionamiento al interior del servicio. O sea, hay que aumentar la calidad no solo en la base, sino también en los equipos que están pensando en cómo mejorar. Yo creo 
que hay experiencias al respecto en Chile que están funcionando bien y eso no se debiera desestimar.

Otro aspecto es que los ministerios se comprometan efectivamente a hacer las prestaciones que se deben en educación, en salud, en formación laboral. Si la nueva institucionalidad no es capaz de canalizar a esas instituciones, a esos grandes ministerios en este ámbito, vamos a estar con los mismos problemas más adelante, vamos a estar parchando con programas de apresto y no con políticas fuertes en esta materia.

Aquí el Estado tiene que jugar un rol distinto. Históricamente, como todo el Servicio Nacional de Menores hasta ahora, buena parte del trabajo con los infractores, incluyendo la ejecución de las sanciones, lo realizan organismos colaboradores que son de carácter privado. A mí me parece que hay un problema de diseño: tenemos personas particulares como delegados de libertad asistida y como encargados de las sanciones de servicios comunitarios. Creo que a lo menos esos delegados debieran ser funcionarios públicos y solo externalizar ciertos servicios, como, por ejemplo, trabajos socioeducativos en el ámbito de violencia, de las drogas o de la formación laboral, pero bajo una supervisión pública más fuerte. El paso que se pudiera dar es que estos delegados dejen de ser privados $y$, por lo tanto, sin mucho poder ni fuerza frente a los tribunales, la Fiscalía, la Defensoría y las instituciones a las cuales tienen que ir a golpear puertas para conseguir un cupo, en una escuela o en un taller. Ellos deben ser funcionarios de este nuevo servicio y eso debiera cambiarse en el proyecto de ley.

Una idea que está dando vueltas entre ciertos especialistas es construir centros de cumplimiento en los territorios, estableciendo espacios que sean públicos y donde puedan converger los funcionarios del nuevo servicio y las instituciones privadas sin fines de lucro que le presten servicios de reinserción social al Estado. Un recinto público que se convierta en un foco de referencia para la comunidad y también para los propios adolescentes, para que se favorezca el cumplimiento.

Por último, también es clave la infraestructura de los centros privativos de libertad de adolescentes. Si bien, comparativamente no es donde se encuentra la inmensa mayoría de los jóvenes en el sistema penal juvenil, urge que haya menos violaciones de derechos por las malas condiciones allí existentes. Para ello hay que equiparlos, mejorar su infraestructura, ampliar sus espacios, aunque no necesariamente construir más centros porque eso invita muchas veces a llenarlos con más jóvenes privados de libertad, pero sí al menos mejorar las condiciones físicas en las que estos se encuentran.

Relacionado con esto, hay que constatar que durante una década funcionaron muy bien las comisiones de supervisión de los centros, operadas entre el Ministerio de Justicia y Unicef. Esa tarea ahora estará en manos de la nueva Defensoría de la Niñez, y el desafío que tiene esa nueva institucionalidad es no bajar los estándares ni la capacidad de supervisión que se creó durante años, sino que mantenerlos y mejorarlos. En esto creo que hay una pregunta que la sociedad y el Estado se tienen que 
hacer y responder a la brevedad: ¿cuán fuerte está el proceso de instalación de dicha Defensoría para que esto se pueda cumplir a corto plazo sin bajar el estándar de lo ya avanzado? Me parece que al respecto hay algunas dudas y mucho que hacer todavía.

\section{Miguel Cillero}

La clave de ese sistema es reconocer que se requiere una agencia especializada estatal en adolescentes infractores. Esta agencia debe hacerse cargo de desarrollar las tareas fundamentales, incluyendo la articulación de una oferta pública de programas debidamente acreditados y que su diseño se base en evidencia. Es conveniente que tenga la responsabilidad directa de la ejecución de las sanciones y medidas que sean privativas de libertad. Asimismo, debe ser la responsable de articular y supervisar todas las actuaciones del sistema de control y ejecución penal de adolescentes, generando coordinaciones con los Tribunales de Justicia, el Ministerio Público y la Defensoría Penal Pública.

La participación de organizaciones privadas sin fines de lucro se debe centrar en prestaciones complementarias vinculadas a las intervenciones directamente dirigidas a favorecer la reinserción social, pero en un sistema donde el Estado tenga una presencia mayor desde el punto de vista de su responsabilidad. Eso no impide, en ningún caso, la participación de privados en programas ambulatorios, pero de cualquier modo debe ser promovida a través de programas acreditados, debidamente basados en evidencia, que se orienten específicamente por resultados y que tengan una presencia territorial. Tenemos una importante disparidad territorial en la oferta en el ámbito de protección, y también en el ámbito de responsabilidad adolescente. Necesitamos hacernos cargo de cuestiones importantes de prevención territorial que van más allá de las que puedan abordarse exclusivamente desde el Ministerio del Interior o de los municipios. Hay que trabajar sobre estos temas de manera vinculada desde el Servicio. Eso requiere un sistema complejo de prevención del delito y de ejecución de sanciones, de una política nacional sobre la materia que se conecte con la política nacional de infancia, y no que se haga solamente desde los ministerios de Justicia o de Interior. Por ello se requiere de una transformación importante y fundamental para que el servicio sea capaz de desarrollar progresivamente, en el sentido de que va a tener que ir modificándolo continuamente, una excelencia técnica en la ejecución de los programas.

Esto supone que el Servicio desarrolle fortalezas de investigación y capacidad de gestionar mucho mejor los sistemas de información para el seguimiento de casos, es decir, un trabajo totalmente distinto a todo lo que se ha venido haciendo. Sobre eso hay muy buenas experiencias internacionales de las cuales aprender y una normativa internacional robusta que debe guiar la estructuración del Servicio.

En el ámbito específico de la protección de los derechos humanos de imputados 
y condenados adolescentes, el Estado tiene un deber de garante de los derechos, especialmente de quienes se encuentren en privación de libertad, para asegurar que se cumplan las condiciones básicas para el desarrollo de los adolescentes y garantizar la prohibición de torturas o tratos crueles, inhumanos o degradantes.

Se debe asegurar que sean sistemas que, como señala la Convención sobre Derechos del Niño y a la normativa internacional, se orienten a favorecer el desarrollo y la integración social de los niños y sean utilizados solo como último recurso y por el período más breve posible.

Los adolescentes están en una etapa de crecimiento y desarrollo, la intervención penal no debe devastar o impedir sus posibilidades de desarrollo. No basta con no causar daño, o asegurarse de que no exista tortura o tratos crueles inhumanos o degradantes, sino que debe favorecerse que ellos puedan ampliar sus posibilidades de vida y modificar aquellas condiciones - personales o sociales- que no favorecen un comportamiento legal. Se trata de apoyar a los adolescentes, especialmente a los que presentan conductas delictivas reiteradas, a transitar hacia una conducta sin delitos, lo que en términos criminológicos se conoce como favorecer el desistimiento.

Para que esto pueda realizarse se requiere de un trabajo especializado en sede de ejecución penal, pero con una intensa coordinación con el servicio de protección de la infancia y con el conjunto de políticas sociales dirigidas a la infancia y la adolescencia, particularmente con educación, salud, vivienda y territorio.

\section{Sobre los entrevistados}

Las entrevistas fueron hechas por Benjamín González Guzmán, Nicolle Chávez Silva y Abril Anais Silva, todos asistentes editoriales de Anuario de Derechos Humanos.

Fabiola Lathrop Gómez es abogada de la Universidad de Chile, doctora en Derecho por la Universidad de Salamanca en 2008. Es Profesora Asociada de la Universidad de Chile e imparte la cátedra de Derecho Civil en la Facultad de Derecho. Fue abogada de la Unidad de Reformas Legales del Servicio Nacional de la Mujer en 2007 y asesora del Ministerio de Desarrollo Social en materia de infancia. Ha sido consultora de Unicef Chile. Dentro de sus libros se destacan El cuidado personal y la relación directa y regular. Estudio exploratorio en los Tribunales de Familia de la Región Metropolitana (2013), Responsabilidad parental (2017) y Custodia compartida de los hijos (2008).

Gonzalo Berríos Díaz es abogado de Universidad de Chile y subdirector de la Escuela de Postgrado de la Facultad de Derecho de la misma universidad. Es magíster en Derecho Penal y Procesal Penal por la Universidad Diego Portales y profesor asistente del Departamento de Ciencias Penales de la Facultad de Derecho de la Universidad de Chile. Se ha desempeñado como abogado encargado del Departamento de Menores del Ministerio de Justicia y Jefe de Gabinete del Defensor Nacional en la 
Defensoría Penal Pública. Fue jefe de la Unidad de Defensa Penal Juvenil de la Defensoría Penal Pública entre los años 2005 a 2016. Es consejero de la Academia Judicial de Chile (2018-2022).

Miguel Cillero Bruñol es abogado de la Universidad de Chile. Doctor en Derecho por la Universidad Pablo Olavide, Sevilla. Profesor del Departamento de Ciencias Penales de la Facultad de Derecho de la Universidad Diego Portales, titular de cátedra de Derecho Penal Juvenil, profesor de postgrado en programas nacionales y extranjeros en derechos humanos de la infancia, familia y justicia penal. Investigador afiliado de la Cátedra de Derecho y Menores de la Universidad Comillas de Madrid. Ha sido consultor de Unicef, Banco Interamericano de Desarrollo, Instituto Interamericano del Niño y actualmente es presidente del Centro Iberoamericano del Derecho del Niño (Cideni). 
El Anuario de Derechos Humanos es una publicación anual de referencia y consulta en derechos humanos y materias afines, que busca ser un espacio de discusión, difusión y conocimiento de los temas centrales sobre derechos humanos en sus contextos nacional e internacional, poniendo a la disposición del público de manera gratuita los distintos desarrollos doctrinales, jurisprudenciales y legislativos ocurridos en este campo dentro del período anual cubierto por cada edición.

\author{
DIRECTORA RESPONSABLE \\ Nancy Yáñez Fuenzalida \\ EDITOR DE CONTENIDOS \\ Salvador Millaleo \\ SITIO WEB \\ anuariocdh.uchile.cl \\ CORREO ELECTRÓNICO \\ anuario-cdh@derecho.uchile.cl
}

LICENCIA DE ESTE ARTÍ́CULO

Creative Commons Atribución Compartir Igual 4.0 Internacional

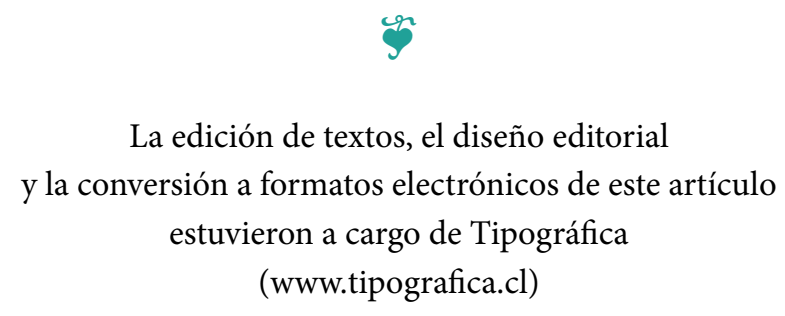

